\title{
The Effects of Hotel Environmental Factors on Consumers' Emotions and Attitudes- The Moderating Effect of Lifestyle
}

\author{
By Man-Ting Wang ${ }^{*}$ \\ Yu-Hua Sun ${ }^{\dagger}$
}

\begin{abstract}
As time changes, this marks the beginning of a new era where consumers are pursuing a higher quality of life. Nowadays most conventional hotels provide customers with elegant and comfortable accommodations, but these types of traditional accommodating settings no longer have the appealing effect to captivate mass audience's interests nor to satisfy their demands. And so this is where the new and refreshing types of hotels come in for breaking the old traditional designed methods used in hotels. Comparing to traditional and conservative hotels, the new innovative hotels use daring visual color variants along with the background music to help stimulate consumer senses and shape their attitudes towards the hotel. Hence, the purposes of this research are hereby threefold: first, to explore whether the hotel environmental factors such as color and music would affect consumers' emotions and perceived quality; second, to explore whether the lifestyle of consumers would moderate the effects of color and music on consumers' emotions and perceived quality. The study will apply experimental method with a 2 $x 2$ factorial design. The independent variables will be color (analogous scheme vs. contrasting scheme) and music (classical vs. Jazz). There will be two mediating variables, one is emotion and the other is perceived quality. Lifestyle will be used as a moderating variable to explore whether it influences the effect of color and music on emotions and attitudes. The dependent variable in this study will be purchasing intention. Subjects must have travel experiences staying at a hotel within the past 6 months to be qualified to participate in the experiment. Qualified subjects will be randomly assigned to one the experimental designs. After viewing photos of different hotel design with different background music played at the same time, subjects will be asked to complete a questionnaire to elicit their current emotions and their attitudes towards to the assigned hotel. Information of subjects' life style and demographic background will be also collected via the questionnaire. Theoretical and managerial implications will be discussed.
\end{abstract}

*Graduate Student, National Taiwan Normal University, Taiwan.

${ }^{\dagger}$ Professor, National Taiwan Normal University, Taiwan. 


\section{Introduction}

In recent years, many hotels have begun to adopt bold and new style, and changed the existing consumer impression of hotels. According to the latest research by Protean Strategie (2012) about 2/3 of the surveyed consumers admitted that they choose hotels by their emotions. For many consumers, they would put feeling above thinking, which is also true in the case of choosing a hotel. Therefore, it is important for the hospitality and tourism industry to spot what attracts consumers the most. This has proved that more and more hotels have come to realize and endeavor to cater to the need of consumers and trigger their desire to purchase (Peck, 2013).

Related research on different industries have shown that the theme color of shopping centers may make the consumers feel delighted and stimulate them to buy more (Bellizzi \& Hite, 1992). Reda (1998) demonstrated the importance of music in retail stores. Meanwhile, in the earlier research on the influence of hotel surrounding on consumers, lifestyle was not included in the discussion. Hence, this study treats the hospitality and tourism industry as the target. The research purposes are as follows: (1) to discuss if environmental factors such as color and music may affect emotion and perceived quality, and further affect one's purchasing intention; (2) to discuss the moderating effect of lifestyle and the correlation between abovementioned environmental factors and such moderation of lifestyle.

\section{Literature Review}

\section{Related Studies on the Influence of Color on Consumers' Attitude}

According to Mehrabian \& Russell (1974) higher visual stimulus triggers excitement while lower visual stimulus triggers depression. The discrepancy between the above stimuli exists not only in how the visual clues are presented, but in the emotions triggered by them. Garvin (1983) suggested that consumers make initial judgment based on the exterior of a shop. In other words, better environmental design may better brand image to the target group, while a relaxing, refined interior design can enhance consumers' confidence in the service provided by the shop. Therefore, this paper suggests that colors may affect consumers' perception. $\mathrm{H} 1$ is proposed as follows:

H1a: The colors of the hotel have a significant influence on consumers' emotions.

H1b: The colors of the hotel have a significant influence on consumers' perceived quality.

\section{Related Studies on the Influence of Music on Consumers' Attitude}

Clynes (1982) indicated the structure of music can be regarded as a key to the nerve of our brain, and can cause emotional response. Appropriate melodies may bring in pleasure and excitement to consumers, thus reducing the 
spirit cost, time, and labor cost, in turn, lengthening the time consumers stay at the shop (Baker, Parasuraman, Grewal, \& Voss. 2002). Furthermore, previous study has demonstrated a correlative link between music and consumers' perceived quality. $\mathrm{H} 2$ is proposed as follows:

H2a: The music played at the hotel has an influence on people's emotions. $\mathrm{H} 2 \mathrm{~b}$ : The music played at the hotel has an influence on people's perceived quality.

\section{The Moderating Effect of Lifestyle}

Martineau (1958) pointed out that no stores can provide all kinds of service or commodity to make every consumer happy, which corresponds to the fact that consumers are inclined to do shopping in the stores that have identical image with themselves. Thus, it is conclude that one's living habits and cultural background may affect their level of satisfaction for a shop. H3 is proposed as follows:

H3a1: The lifestyle of consumers affects the relationship between colors and emotions.

H3a2: The lifestyle of consumers affects the relationship between colors and the perceived quality.

H3b1: The lifestyle of consumers affects the relationship between music and emotions;

H3b2: The lifestyle of consumers affects the relationship between music and the perceived quality.

\section{Factors Affecting the Purchasing Intention}

Isen \&Means (1983) conducted a series of experiments on consumers, and found that the change of emotions affects the purchase attitude and intentions. The results indicated that consumers with positive emotions spend less time than those with neutral emotions in making the purchase decision. With regard to the relation between the perceived quality and customers' purchasing intention, Chaudhuri (2002) proposed that the perceived quality plays a crucial role in affecting consumers' satisfaction. In other words, higher perceived quality leads to more readiness to purchase. Tslotsou (2006) found that the perceived quality and purchasing intention are positively correlated; hence, the perceived quality is an effective indicator toward purchasing intention. $\mathrm{H} 4$ is proposed as follows:

H4a: Consumers' emotions affect their purchasing intention.

$\mathrm{H} 4 \mathrm{~b}$ : Consumers' perceived quality affects their purchasing intention.

Based on the above, the research framework is developed, as shown in Figure 1: 
Figure 1. Conceptual Model

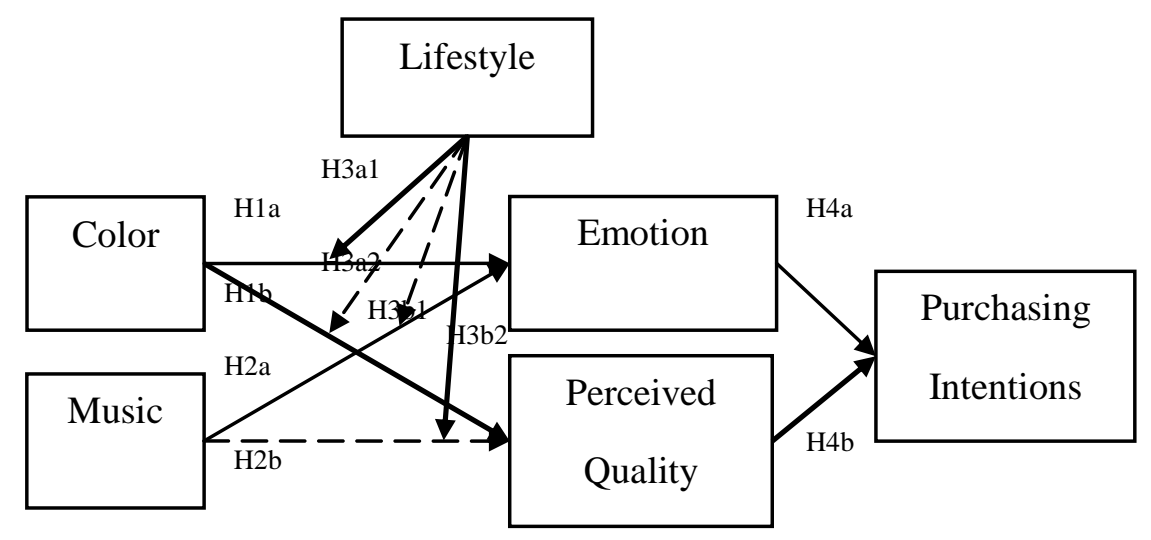

\section{Method}

\section{Research Subjects}

This study selected the consumers who have stayed at international tourism hotels in Taiwan within the past six months as the subjects. By convenience sampling, the subjects were randomly shown with a set of experimental design. Music was played in the background when the subjects were viewing the pictures. Then, the subjects were asked to fill out a questionnaire concerning their attitude and emotion toward the hotel shown in the picture. A total of 165 questionnaires were delivered. After eliminating 5 invalid samples, there were 160 effective samples, with a valid return rate of $96.38 \%$.

\section{Experimental Design}

The experimental environment was set on tablets, where the researcher designs the hotel space, selected background music, simulated the real scenario, and manipulated the variables. The questionnaire was based on the 2 (color: analogous color vs. contrasting color) * 2 (music: classical music vs. jazz music) between-subject design, with four types of experiment.

\section{Research Tools}

This study used the questionnaire as a tool for data collection, which consists of six parts, namely lifestyle, emotions, perceived quality, purchasing intentions, manipulative testing and demographic statistics. All parts, except for the demographic statistics, were based on a Likert 7-point scale, ranging from 1 (strongly disagree) to 7 (strongly agree). The scale for lifestyle referred to Strategic Business Insights (1989), with 35 items; the scale for emotions referred to Mehrabian (1996), with 18 items; the scale for perceived quality referred to Dodds, Monroe and Grewal (1991), Erevelles, Abhik and Stephen (1999), with 4 items; the scale for purchasing intention referred to Zeithaml, Berry \& Parasuraman (1996), with 4 items. 
Data Analysis

One-way ANOVA, multivariate analysis, regression analysis and reliability and validity analysis. The results suggest that $\mathrm{KMO}>0.8$, Bartlett's ball-shaped testing $\mathrm{p}<.001$, explanation of variance $>70 \%$, suggest that the reliability of factor analysis is good. Cronbach $\alpha>0.7$, indicating good validity.

\section{Results}

\section{Demographic Analysis}

The demographic statistics and distribution are explained as follows. There are 48 male subjects (30\%), and 112 female subjects (70\%). The number of females is more than that of males. There is only one subject below the age of $20(0.6 \%)$, there are 86 subjects who are between the age of $21 \sim 30(53.8 \%), 21$ are between the age of 31 40 (13.1\%), and 41 are between the age of 41 50 $(25.6 \%)$. There are 81 subjects with educational level below high school and vocational school (11.3\%), 76 have university degree $(47.5 \%)$, and 66 have graduate degree $(41.3 \%)$. There are 58 students $(36.5 \%), 44$ subjects in the service industry $(27.1 \%), 22$ in the business field (13.8\%), and 20 public servants, teachers, or servicemen (12.6\%). There are 107 single subjects $(66.9 \%)$, and 51 married subjects (31.9\%). There are 62 subjects with a monthly income less than NTD 20,000 (38.8\%), followed by 43 with a monthly income of NTD20,001 40,000 (26.9\%) and 31 with a monthly income of 40,001 60,000 (19.4\%).

\section{Manipulative Testing Analysis}

This study conducted t-test to determine if there is any difference between the impacts of "analogous colors" and "contrasting colors". The item "I think the arrangement of colors should be classified as analogous colors" shows a significant difference $(\mathrm{t}=8.293, \mathrm{p}<.001)$, as the mean of "analogous colors" ( $\bar{X}=5.0500, S D=1.32072$ ) is obviously higher than that of "contrasting colors" ( $\bar{X}=3.1899, \mathrm{SD}=1.50278$ ). The item "I think the arrangement of colors should be classified as contrasting colors" $(\mathrm{t}=-4.525, \mathrm{p}<.001)$ can distinguish the mean of two groups, as the mean of "contrasting colors" ( $\bar{X}=4.4125, \mathrm{SD}=1.66645)$ is higher than that of "analogous colors" ( $\bar{X}=3.2750, \mathrm{SD}=1.50925)$, which indicates successful manipulation of colors in an interior design.

This study also conducted a t-test to determine if there is any difference between the impacts of "classical music" and "jazz music". The item "I think the background music in the film should be classified as classical music" shows a significant difference $(\mathrm{t}=9.300, \mathrm{p}<.001)$, as the mean of "classical music" ( $\bar{X}=4.7125, S D=1.72248)$ is obviously higher than that of "jazz music" ( $\bar{X}=2.4304, \mathrm{SD}=1.34625$ ). The item "I think the background music in the film should be jazz" ( $\mathrm{t}=-11.023, \mathrm{p}<.001)$ can distinguish the mean of two groups, as the mean of "jazz music" ( $\bar{X}=5.2625, \mathrm{SD}=1.57306)$ is higher than that of "classical music" ( $\bar{X}=2.5625, \quad S D=1.52485)$, which indicates successful manipulation of background music. 
Testing of Hypothesis

The Relationship between the Color and Music of a Hotel and the Emotion and Perceived Quality of Consumers

To better grasp the influence of color and music on emotions and perceived quality, this study conducted multivariate analysis to verify $\mathrm{H} 1$ and $\mathrm{H} 2$. The results suggest that a significant difference exists in the arousal $(\mathrm{F}=.207, \mathrm{p}=.054)$ and the perceived quality $(\mathrm{F}=2.99, \mathrm{p}=.086)$ with $\mathrm{p}<0.1$ as the standard. Wilkes lambda is .971 ( $\mathrm{p}>.05)$. Thus H1a is partly supported and $\mathrm{H} 1 \mathrm{~b}$ is supported.

Table 1. The Average Summary of Color on Emotion and Perceived Quality

\begin{tabular}{|c|c|c|c|c|}
\hline $\begin{array}{c}\text { Dependent } \\
\text { variable }\end{array}$ & $\begin{array}{c}\text { Independent } \\
\text { variables }\end{array}$ & Mean & SD & $\mathbf{F}$ \\
\hline Emotion & & & & \\
\hline \multirow{2}{*}{ Pleasure } & Analogous & 4.927 & 1.30261 & \multirow{2}{*}{3.771} \\
\hline & Contrast & 4.490 & 1.53747 & \\
\hline \multirow{2}{*}{ Arousal } & Analogous & 3.690 & 1.14380 & \multirow{2}{*}{$.207 \dagger$} \\
\hline & Contrast & 3.773 & 1.17050 & \\
\hline \multirow{2}{*}{ Dominance } & Analogous & 4.329 & .90792 & \multirow{2}{*}{1.264} \\
\hline & Contrast & 4.131 & 1.28271 & \\
\hline \multirow{2}{*}{ Perceived quality } & Analogous & 4.963 & .94140 & \multirow{2}{*}{$2.993 \dagger$} \\
\hline & Contrast & 4.656 & 1.27312 & \\
\hline
\end{tabular}

There is a significant difference in pleasure $(\mathrm{F}=17.556, \mathrm{p}=.003)$ and manipulation $(\mathrm{F}=5.831, \mathrm{p}=.017)$ in differing music background, with Wilk ${ }^{\text {ee }}$ lambda as .943 ( $\mathrm{p}<.05)$. Thus $\mathrm{H} 2 \mathrm{a}$ and $\mathrm{H} 2 \mathrm{~b}$ are not supported.

Table 2. The Average Summary of Music on Emotion and Perceived Quality

\begin{tabular}{|c|c|c|c|c|}
\hline $\begin{array}{c}\text { Dependent } \\
\text { variable }\end{array}$ & $\begin{array}{c}\text { Independent } \\
\text { variables }\end{array}$ & Mean & SD & $\mathbf{F}$ \\
\hline Emotion & & & & \\
\hline \multirow{2}{*}{ Pleasure } & classical & 4.377 & 1.61953 & \multirow{2}{*}{$17.556 *$} \\
\hline & jazz & 5.040 & 1.14560 & \\
\hline \multirow{2}{*}{ Arousal } & classical & 3.640 & 1.15575 & \multirow{2}{*}{1.344} \\
\hline & jazz & 3.823 & 1.15287 & \\
\hline \multirow{2}{*}{ Dominance } & classical & 4.021 & 1.24422 & \multirow{2}{*}{$5.831 * *$} \\
\hline & jazz & 4.439 & .92344 & \\
\hline \multirow{2}{*}{$\begin{array}{l}\text { Perceived } \\
\text { quality }\end{array}$} & classical & 4.747 & 1.25063 & \multirow{2}{*}{$.491 *$} \\
\hline & jazz & 4.872 & .99125 & \\
\hline
\end{tabular}

The Moderating Effect of Lifestyle

To better understand whether lifestyle can moderate the relationship between the hotel's environment and customers' emotion and perceived quality, this study conducted multivariate analysis to verify H3. The influences of colors on the three constructs of emotions become more obvious after they are moderated by lifestyle, which suggests that consumers' lifestyle can moderate colors and emotions. Hence, H3a1 is supported. The influence of 
colors on the perceived quality becomes less obvious, which suggests that consumers' lifestyle has no moderating effect on colors and emotions. Hence, $\mathrm{H} 3 \mathrm{a} 2$ is not supported. The influence of music on the three constructs of emotions remains almost the same; hence, $\mathrm{H} 3 \mathrm{~b} 1$ is not supported. The influence of music on the perceived quality turns more obvious once it is moderated by lifestyle, which means that consumers' lifestyle can moderate music and perceived quality; therefore $\mathrm{H} 3 \mathrm{~b} 2$ is supported.

Table 3. Results of testing Moderator Effect of Lifestyle

\begin{tabular}{|c|c|c|c|}
\hline $\begin{array}{c}\text { Independent } \\
\text { variables }\end{array}$ & $\begin{array}{c}\text { Dependent } \\
\text { variable }\end{array}$ & $\mathbf{F}$ & Lifestyle \\
\hline \multirow{4}{*}{ Color } & Pleasure & 2.217 & $3.161^{*}$ \\
\cline { 2 - 4 } & Arousal & .160 & $4.937^{* *}$ \\
\cline { 2 - 4 } & Dominance & .586 & $3.062^{*}$ \\
\cline { 2 - 4 } & Perceived Quality & $4.933^{*}$ & 2.136 \\
\hline \multirow{4}{*}{ Music } & Pleasure & 1.832 & .739 \\
\cline { 2 - 4 } & Arousal & $4.342^{*}$ & 2.496 \\
\cline { 2 - 4 } & Dominance & .040 & .831 \\
\cline { 2 - 4 } & Perceived Quality & .016 & $.547^{*}$ \\
\hline
\end{tabular}

The Relationship between Emotions and the Perceived Quality and One's Purchasing Intention

The pleasure $(\beta=.611, t=6.806, p=.000)$ and the perceived quality $(\beta=.505$, $\mathrm{t}=7.585, \mathrm{p}=.000$ ) have apparent influence on one's purchasing intention; hence, $\mathrm{H} 4 \mathrm{a}$ is partly supported and $\mathrm{H} 4 \mathrm{~b}$ is supported. From the above Beta coefficient, it is inferred that the most important factor to the purchasing intention is one's perceived quality, followed by pleasure. $\mathrm{R} 2=.516 \%$, adjusted $\mathrm{R} 2=.507 \%$ $\mathrm{F}=55.466$.

Table 4. Emotions and perceived Quality on Purchase Intentions Regression Analysis

\begin{tabular}{|c|c|c|}
\hline & Beta & t \\
\hline Emotion & & \\
\hline Pleasure & .611 & $6.806^{* * *}$ \\
\hline Arousal & .083 & 1.348 \\
\hline Dominance & .119 & 1.243 \\
\hline $\mathrm{R}^{2}=.516 \%$ Adjusted R-square $=.507 \% \mathrm{~F}=55.466$ & $7.585^{* * *}$ \\
\hline Perceived quality & .505 & \\
\hline $\mathrm{R}^{2}=.607 \%$ Adjusted R-square $=.604 \% \quad \mathrm{~F}=243.902$ & \\
\hline
\end{tabular}

\section{Conclusion and Suggestions}

\section{Conclusion and Discussion}

This study found that the color of the interior design may affect one's arousal and perceived quality. Background music of a hotel may have an 
influence on consumers' pleasure, dominance, and perceived quality. One's lifestyle may moderate the effect brought by colors/music on emotion/ perceived quality. Pleasure and perceived quality may have significant influences on one's purchasing intention.

This study has a different manipulative method than those recorded in the past literature by adopting "analogous colors" and "contrasting colors" instead of "warm colors" and "cold colors". With the selection of music, this study chose differing types of music: classical music and jazz music. The presentation of the experiments has more realness and beauty than the past literature.

\section{Research Limitations and Suggestions}

This study adopted experimental method to manipulate the virtual scenarios. As the subjects viewed the images and filled out the questionnaire at the same time, they might not be fully immersed in the scenario. It is possible that the subjective consciousness of the subjects might affect the research results. Thus, this study failed to control the authenticity of the scenario for the subjects.

For future studies, this study suggests that field investigation on the hotel guests is more effective in understanding their feelings and enhance the accuracy of the research results. Although questionnaire survey is beneficial to analysis, the consumers' feedbacks are limited, thus, this study could not probe into the true feelings of the subjects. Future studies can adopt qualitative research.

\section{References}

Baker, J., Parasuraman, A., Grewal, D., \& Voss, G. B. 2002. The influence of multiple store environment cues on perceived merchandise value and patronage intentions. Journal of marketing, 66 (2), 120-141.

Bellizzi, J. A., \& Hite, R. E.1992. Environmental color, consumer feelings, and purchase likelihood. Psychology \& marketing, 9 (5), 347-363.

Chaudhuri A. 2002. Chronic fatigue syndrome and myalgic. encephalomyelitis. 359:1698-9.

Clynes, M. 1982. Music, mind, and brain: The neuropsychology of music (Vol. 94). Plenum Pub Corp.

Dodds, W. B., Monroe, K. B., \& Grewal, D. 1991. Effects of price, brand, and store information on buyers' product evaluations. Journal of Marketing Research (JMR), 28 (3).

Erevelles, Sunil, Abhik Roy and Stephen L. Vargo. 1999, The Use of Price and Warranty Cues in Product Evaluation: A Comparison of US and Hong Kong Consumers, Journal of International Consumer Marketing, 11 (3), 67-91.

Garvin, D. A. 1983. Quality on the line. Harvard business review, 61 (5), 65-75.

Isen, A. M., \& Means, B. 1983. The influence of positive affect on decision-making strategy. Social cognition, 2 (1), 18-31.

Martineau, P. 1958. The personality of the retail store. 
Mehrabian, A. 1996. Pleasure-arousal-dominance: A general framework for describing and measuring individual differences in temperament. Current Psychology, 14 (4), 261-292.

Mehrabian, A., \& Russell, J. A. 1974. An approach to environmental psychology. the MIT Press.

Protean Strategies. 2012. Study Shows Hotel Choice is More Emotionally Driven than Beer...But Major Hotel Brands Fall Short in Appealing to Emotions. Retrieved from http://issuu.com/lbernste/docs/protean_hotel_brand_emotion_study_over view 1 ? $=1505419 / 1242278$

Reda, S. 1998. Targeted store music programs strengthen ties between sound and sales. Stores, 80, 54-6.

Strategic Business Insights (1989). The US VALS ${ }^{\mathrm{TM}}$ Survey. Retrieved May19, 2014, from http://www.strategicbusinessinsights.com/vals/surveynew.shtml

Tim Peck. 2013. Designing for emotions. HotelNewsNow.com Web site: http://www. hotelnewsnow.com/Article/10151/CapEx-requirements-pick-up-in-2013.

Tsiotsou, R. 2006. The role of perceived product quality and overall satisfaction on purchasing intentions. International Journal of Consumer Studies, 30 (2), 207217.

Zeithaml, V. A., Berry, L. L., \& Parasuraman, A. (1996). The behavioral consequences of service quality. Jou 
